\title{
Competition in the Outsourced Chief Investment Officer Market: A Game Theory Approach"
}

\author{
Daehyeon Park, Ph.D. Candidate, Sungkyunkwan University \\ Doojin Ryu ${ }^{* *}$, Professor, Sungkyunkwan University
}

\begin{abstract}
$\langle$ Abstract $\rangle$
This study analyzes the competition in the outsourced chief investment officer (OCIO) market by utilizing a game-theory approach of multidimensional auctions, which is theoretically identical to the procurement auction system of OCIO selection. Depending on how the OCIO manages the fund, we analyze auctions using two distinct cases. In the first case, the OCIO operates a designated organization for each fund. This case leads to the conclusion that it is difficult for small funds to use OCIO services because of the high operational costs. In the second case, the OCIO manages multiple funds collectively, enabling even small funds to use OCIO services. Korea's OCIO market currently operates according to the premise of the first case, meaning that small private funds are not likely to use the service even if a fund-type retirement pension is introduced. Thus, our conclusion implies that in the current OCIO structure, it is difficult for the Korean OCIO market to grow significantly. Policies and institutional supplementation are required.
\end{abstract}

Keywords: Competition; Game Theory; Multidimensional Auction; Outsourced Chief Investment Officer; Procurement Auction

JEL Classification: D86, G11, G23

* This research was supported by New Scholars Grant Program from the Korean Securities Association and Mirae Asset in 2020.

** Corresponding Author. Address: College of Economics, Sungkyunkwan University, 25-2, Sungkyunkwan-ro, Jongno-gu, Seoul, Korea, 03063; E-mail: sharpjin@skku.edu; Tel: +82-2-760-0429; Fax: +82-2-760-0950.

Received: March 2, 2021; Revised: April 9, 2021 \& May 7, 2021 \& June 4, 2021; Accepted: June 8, 2021 


\title{
OCIO 시장에서의 경쟁: 게임이론의 응용
}

\author{
박 대 현 (성균관대학교 박사과정) \\ 류 두 진 (성균관대학교 교수)**
}

\begin{abstract}
본 논문은 $\mathrm{OCIO}$ (outsourced chief investment officer) 시장에서의 경쟁을 게임이론과 경매이론을 활용해 분석한다. 본 연구에서는 다차원 경매 모형의 틀 하에서 개별 기금의 OCIO 선정 경쟁을 하나의 경매과정으로 구성한다. OCIO가 기금을 운용하는 방식에 따라 두 가지 경우로 나눠 분석한다. 첫 번째 운용방식은 기금별로 전담조직을 구성하여 운용하는 형태이다. 이 경우, 규모가 작은 기금은 전담조직 구성에 필요한 비용으로 인해 OCIO 서비스를 사용할 유인이 적다. 두 번째 운용방식은 OCIO가 여러 기금을 총괄적으로 운용하는 형태이다. OCIO가 여러 기금을 총괄적으로 운용하면 규모가 작은 기금도 OCIO 서비스를 사용할 수 있다. 현재 국내 OCIO 시장은 첫 번째 운용방식과 같이 기금별로 전담조직을 구성하여 OCIO 서비스를 제공하는 상황에 해당한다. 이는 기금형 퇴직연금의 도입이 OCIO 시장의 성장을 보장하지 않는다는 것을 의미한다. 본 논문의 분석결과는 현재와 같은 OCIO 사업구조가 유지될 경우, $\mathrm{OCIO}$ 시장의 규모가 급격히 성장하기는 어려우며, 이에 따른 정책과 제도적 보완이 필요할 수 있음을 시사한다.
\end{abstract}

핵심 단어 : OCIO, 게임이론, 경쟁, 다차원 경매, 조달 경매

JEL 분류기호: D86, G11, G23

* 본 연구는 2020년 한국증권학회-미래에셋자산운용 신진학자 연구지원사업의 연구지원을 받아 수행되었습니다. 본 논문은 2021년 한국증권학회 정기학술발표회, 재무금융 공동학술대회, 한국금융 학회 정기학술대회에서 발표되었습니다. 유익한 조언을 주신 이동욱 편집위원장님, 김태종 교수님, 박영규 교수님, 빈기범 교수님, 정영식 선임연구위원님, 조훈 교수님, 강창기 서기관(기재부), 고윤 조사역(금감원), 이우혁 상무(미래에셋), 임동용 차장(한투운용), 조진형 조사역(금감원), 주효근 박사(한화운용), 한민연 박사(미래에셋), 황수욱 연구원(메리츠증권)께 감사드립니다.

** 연락담당 저자. 주소: 서울특별시 종로구 성균관로 25-2 성균관대학교 경제학과, 03063; E-mail: sharpjin@skku.edu; Tel: 02-760-0429; Fax: 02-760-0950. 


\section{1. 서론}

기금형 퇴직연금 제도의 도입이 기대되면서 OCIO(outsourced chief investment officer) 시장의 규모가 증가할 것이라는 전망이 제시되고 있다. 이에 따라 OCIO 시장을 선점하기 위해 투자운용사 간의 경쟁이 치열하다. OCIO 서비스는 자산소유자(asset owner)가 자산운용의 전반을 외부의 자산운용자(asset manager)에게 위탁하는 서비스로, 전통적 위탁방식과 달리 전략적 의사결정에 대한 권한까지 포괄적으로 위임하여 종합적인 자산관리 서비스를 제공하는 것이 특징이다. 국내에서는 기획재정부에 의해 공적 연기금 투자풀(investment pools)이 도입된 이후로 다양한 공적 연기금이 OCIO 형태로 자산을 운용하고 있다. 최근에는 기금형 퇴직연금 제도가 도입될 것으로 기대됨에 따라 민간기금의 수요도 증가할 것이라는 전망이 이어지고 있다. 이로 인해 $\mathrm{OCIO}$ 시장의 규모가 증가하리라는 기대가 형성되면서 다양한 운용사와 증권사가 $\mathrm{OCIO}$ 공급시장을 선점하기 위해 경쟁하고 있다. 한국투자증권은 고용보험기금을 운용하고 있다. 삼성자산운용은 산재보험기금을 운용하고 있으며, 공적 연기금 투자풀을 운용하고 있다. 한국투자신탁운용은 삼성자산운용과 함께 공적 연기금 투자풀을 운용해 왔으며, 민간기금을

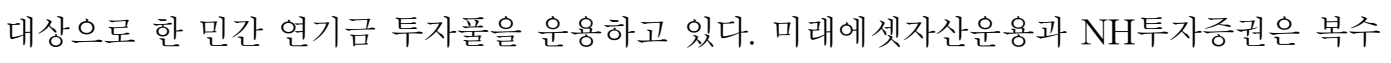
주간운용사로 주택도시기금을 운용하고 있으며, 미래에셋자산운용은 2021년 경쟁입찰에서 기존 주간운용사인 한국투자신탁운용을 대신하여 공적 연기금 투자풀의 주간운용사로 선정되었다.

현재 국내 $\mathrm{OCIO}$ 시장 상황에서는 공급자 측의 경쟁으로 인하여, OCIO 서비스의 보수가 해외에 비해 낮게 형성되는 측면이 있다.1) $\mathrm{OCIO}$ 의 보수는 운용보수와 성과보수로 나뉜다. 운용보수는 실적과 무관하게 운용대상인 기금의 크기에 따라 결정되는 보수이다. 반면, 성과 보수는 대리인 문제를 해소하기 위해 제공되는 일종의 인센티브(incentive)로, 벤치마크 (benchmark) 수익률 대비 초과수익률에 따라 결정된다. 국내 OCIO 시장의 경우 성과보수가 거의 지급되고 있지 않으므로, $\mathrm{OCIO}$ 공급기업은 운용보수를 통한 수입만을 기대한다. 그러나 운용보수는 OCIO 시장의 도입기인 2000년대 초반에는 $8 \mathrm{bp}$ 에서, 2020 년에는 평균 $4 \mathrm{bp}$ 수준으로 하락하였다.2) 이는 $8 \mathrm{bp}$ 정도로 유지되는 해외의 사례와 비교하면 절반 수준이며, 기금의 규모가 충분히 크지 않다면 $\mathrm{OCIO}$ 체계를 구축하고 전문인력을 동원하는 등 고정적으로 발생하는 비용을 충당하기 어려울 수 있다. 운용보수가 이처럼 낮아지는 추세는 공급자 측의 경쟁이 증가함에 따라 나타난 현상으로 보인다.3)

$\mathrm{OCIO}$ 시장에서 공급자 측의 경쟁은 추후 기금형 퇴직연금제도의 도입에 대한 전망과 관련된다. 지난 20 대 국회에서 퇴직연금에 관한 법안이 발의되었으나, 폐기되어 현재 국내에서는 기금형

1) 남재우, “국내 OCIO 제도 정착을 위한 개선과제," 『이슈보고서』, 자본시장연구원, 19-05, 2019.

2) 남재우, “최근 국내 OCIO 시장 확대에 관한 소고," 『자본시장포커스』, 자본시장연구원, 2020-21호, 2020.

3) 해외 $\mathrm{OCIO}$ 의 경우와 비교하여 국내 $\mathrm{OCIO}$ 의 운용보수가 낮은 이유가, 자산운용자간의 과도한 경쟁 이외에도, 절대적인 인건비와 사업운용 비용이 낮기 때문일 수도 있다. 또한, 자산소유자와 자산운용자 간의 협상력(bargaining power) 차이에 기인한 것일 수도 있다. 이와 관련하여 유익한 조언을 주신 심사위원님께 감사드립니다. 
퇴직연금이 도입되지 않은 상황이다. 그러나 21 대 국회에서 다시 발의되었으며, 학계와 업계 에서도 기금형 퇴직연금 도입에 대한 논의가 계속되고 있다. 국내의 계약형 퇴직연금제도가 갖는 구조적 문제와 운용에서의 비효율성 등을 근거로 향후 국내에도 기금형 퇴직연금이 도입될 것으로 전망된다.4) 현행 계약형 퇴직연금제도는 기업이 퇴직연금 사업자인 금융회사와 계약을 맺고 제도운영과 적립금 운용을 위탁하는 방식으로, 퇴직연금 가입자인 근로자가 적립금 운용에 참여하기 어렵다는 점과 퇴직연금 사업자에게 과도하게 의존한다는 점이 문제로 제기되고 있다. 이와 달리 기금형 퇴직연금제도는 기업이 별도의 수탁법인으로 기금을 설립하고 이를 통해 퇴직연금을 관리하고 운용하는 구조로, 운용위원회 구성원에 근로자 대표를 포함하는 등의 방법을 통해 다양한 이해관계를 반영할 수 있다.

기금형 퇴직연금제도가 도입되고 다수의 퇴직연금이 OCIO 서비스를 사용하게 되면, 국내 퇴직연금의 $\mathrm{OCIO}$ 수요만큼 시장의 규모가 커질 것이다. 따라서 공적 기금을 주요 고객으로 하는 현재의 국내 $\mathrm{OCIO}$ 시장에 다수의 사적연금이 고객으로 부상할 가능성이 크다.5) 선진국의 경우, 기업의 퇴직연금을 포함하여 대학기금이나 재단 등 사적 연기금도 OCIO 서비스를 사용하고 있으며, 최근 국내에서는 삼성자산운용이 서울대학교 발전기금과 이화여자대학교 대학기금의 $\mathrm{OCIO}$ 로 선정되었다.6) 이는 추후 사적 연기금의 참여로 국내 $\mathrm{OCIO}$ 시장의 규모가 성장할 수 있음을 보여준다. 이에 따라 운용사와 증권사는 $\mathrm{OCIO}$ 시장을 선점하려 경쟁하고 있다. 단기적으로는 낮은 운용보수로 인해 수익성이 낮지만, 운용 이력을 남겨 시장을 선점함으로써 규모가 커진 $\mathrm{OCIO}$ 시장에서 지배적인 위치를 차지하고자 경쟁을 이어가는 것으로 보인다.

하지만 기금형 퇴직연금이 도입되더라도 OCIO 시장의 규모가 기대한 만큼 증가할 것이라고 단언할 수는 없다. 현재 국내 OCIO 시장은 대형 공적 기금을 중심으로 운영되고 있으며, 대부분의 $\mathrm{OCIO}$ 서비스는 기금별로 전담조직을 구성하여 기금을 운용하는 형태를 띤다. OCIO 서비스를 사용하는 대형 공적 기금은 전담인력으로 부서를 구성할 것을 요구하고 있으며, 전담인력의 규모 및 우수성은 정성평가의 주요 항목이다. 이는 해외의 OCIO 사례와 차이를 보인다. 해외의 경우, $\mathrm{OCIO}$ 가 다수의 연금에 대한 총괄관리라는 개념으로 성장하고 있다. 이와 달리 국내에서는 $\mathrm{OCIO}$ 가 기금 내부에 있던 운용조직을 단순히 외부로 옮긴 정도의 역할로 제한되어 있다. 이에 따라 OCIO 서비스가 갖는 핵심적인 기능인 전략적 의사결정에 대한 위임도 소극적인 편이다. 최근 국내 $\mathrm{OCIO}$ 시장에서 전담조직의 인력 규모와 수준이 높아지고 있지만, 운용사 간의 경쟁으로 운용보수는 낮게 유지되어 수익성이 악화될 수 있다. 2021년에 공적 연기금 투자풀의 OCIO로 선정된 미래에셋자산운용은 30명 규모의 전담조직을 구성하였으며, 방사성폐기물관리기금의 $\mathrm{OCIO}$ 로 재선정된 신한자산운용은 10 명 이상의 전담인력을 구성하고 있다. 현재의 운용보수의 수준을 고려하면 전담조직의 유지는 운용사에게 부담이 될 수 있다. 전담조직 구성의 부담이 커지면 큰 초기투자비용으로 인해 일부 대형운용사 외에는 시장에 진입하기 어렵게 만드는

4) 남재우, “기금형 퇴직연금제도의 의의와 도입 방향," 『이슈보고서』, 자본시장연구원, 18-02, 2018.

$5)$ 김재칠, “글로벌 아웃소싱CIO(OCIO) 시장의 부상과 시사점," 『자본시장 Weekly』, 자본시장연구원, 2016-28호, 2016.

6) “삼성운용, 외부위탁운용 $(\mathrm{OCIO})$ 깃발꽂기 속도," 한국금융, 2020년 11월. 
한국증권학회지 제50권 5호 (2021)

장벽으로 작용한다. 또한, 현재는 시장 선점을 위해 낮은 운용보수를 제시하고 있지만, 시장을 선점한 후에는 $\mathrm{OCIO}$ 가 전담조직 구성으로 인한 비용을 보상받기 위하여 높은 운용보수를 요구할 가능성이 크다. 기금형 퇴직연금제도가 도입된 이후에 소규모 민간기금이 OCIO 서비스 사용을 희망할 경우, $\mathrm{OCIO}$ 는 비용상의 문제로 높은 운용보수를 요구할 가능성이 있으며, 이 경우 상당수의 민간기금은 $\mathrm{OCIO}$ 서비스를 사용할 유인이 줄어들게 된다. 즉, 현재의 국내 $\mathrm{OCIO}$ 체계에서는 기금형 퇴직연금 제도가 도입되더라도 OCIO 시장의 수요가 충분히 성장할 것이라 기대하기 어려울 것이다. 반면, 해외의 사례와 같이 OCIO가 여러 기금을 통합하여 총괄적으로 운용할 경우, 소규모의 기금에 대한 운용보수의 부담이 줄어들어 OCIO 서비스를 사용할 가능성이 있다.

본 연구에서는 이러한 국내 OCIO 시장의 구조와 상황, 그리고 균형을 경매(auction)에 관한 게임이론(game theory)을 통해 체계적으로 분석한다. 개별 기금은 자신의 계약주기에 맞춰 $\mathrm{OCIO}$ 선정과정을 진행한다. 계약 기간은 기금마다 다를 수 있으나, 국내 OCIO는 보통 4년 정도이며, 기존 $\mathrm{OCIO}$ 계약이 종료되면 기금은 $\mathrm{OCIO}$ 선정과정을 새롭게 진행한다. 기금은 수익률과 위험관리능력과 같이 $\mathrm{OCIO}$ 서비스와 관련된 여러 평가 기준을 제시하고, $\mathrm{OCIO}$ 선정계획을 공지한다. 일반적으로 재무건전성과 전문인력수, 경력 등의 정량적인 운용역량 관련 지표, 운용성과 등에 관한 정량평가와 투자 프로세스, 컴플라이언스(compliance) 시스템 등을 포함하는 정성평가로 구분된다. OCIO로 지원을 희망하는 운용사는 기금이 제시한 평가항목을 바탕으로 서류를 준비하여 지원하며, 필요에 따라 구술심사를 통해 평가받기도 한다. 기금은 평가 기준에 따라 각 운용사를 평가하고 상호 비교하여 가장 높은 점수를 획득한 운용사를 $\mathrm{OCIO}$ 로 선정한다.

기금이 $\mathrm{OCIO}$ 를 선정하는 과정은 두 가지 관점에서 검토할 수 있다. 첫 번째는 불확실성 하에서 기금의 의사결정에 초점을 맞추는 것이다. 기금은 여러 평가 기준에 따라 $\mathrm{OCIO}$ 를 선정하기 희망하지만, 운용사가 제시한 정보를 완벽하게 신뢰할 수 없으며, 모든 정보를 완벽하게 파악할 수 없다. 이러한 상황에서 기금이 직관적으로 최적의 판단을 할 수 있는 알고리즘을 연구하는 방향으로 분석할 수 있다. 이러한 맥락에서 다양한 알고리즘이 제안되고 있다(Ip et al., 2003; Mladineo et al., 2017). 하지만 이러한 분석은 개별 기업의 최적 의사결정에 집중하기 때문에 시장 전반에 대한 충분한 함의를 도출하기 부적합할 수 있다. 두 번째는 기금의 OCIO 선정과정을 하나의 경매로 보고 분석하는 것이다. 기금이 $\mathrm{OCIO}$ 를 선정하는 과정을 살펴보면 일종의 조달 경매(procurement auction)에 해당한다고 할 수 있으며, 여러 평가요소를 고려하는 다차원 경매(multidimensional auction) 모형으로 분석할 수 있다. 다차원 경매에서는 입찰자(bidder)가 제시한 조건을 바탕으로 평가점수(score)를 산정하고, 가장 높은 평가점수를 받은 입찰자가 낙찰을 받는다. 이러한 접근 방법은 앞선 방식에 비해 기금의 의사결정을 단순화하지만, 기금과 운용사의 의사결정을 모두 고려할 수 있으며, 이에 따라 시장 전체에 대한 경제학적 함의를 도출할 수 있다. 이에 따라 본 논문에서는 개별 기금에서의 OCIO 선정과정을 하나의 경매로 보고, 각각의 기금에 대해 운용사가 $\mathrm{OCIO}$ 선정 경쟁에 참여하는 상황을 분석하여 균형을 도출한다.

본 논문에서는 $\mathrm{OCIO}$ 가 기금을 운용하는 방식에 따라 시장 균형이 다르게 도출될 수 있음을 
Competition in the Outsourced Chief Investment Officer Market

고려하여 서로 다른 기금 운용방식을 비교한다. 첫 번째는 현재 국내 OCIO 시장에서 활용되는 방식으로, 기금별로 전담조직을 구성하여 운용하는 형태이다. 두 번째는 해외에서 주로 발견되는 사례로, OCIO가 여러 기금을 총괄적으로 관리하여 운용하는 형태이다. 분석결과, OCIO 운용 방식과 상관없이 운용역량이 높은 소수의 운용사가 시장을 독과점하게 될 가능성이 있다. OCIO 운용방식이 기금별로 전담조직을 구성하는 형태일 경우, 소규모 기금은 높은 운용보수로 인한 비용부담 때문에 OCIO 서비스를 사용할 유인이 없게 된다. 반면, OCIO가 총괄적으로 여러 기금의 자산을 운용할 경우, 소규모의 기금도 OCIO 서비스를 적은 비용으로 사용할 수 있게 된다.

본 논문의 연구방법론은 경쟁의 측면에서 OCIO 시장을 분석한다는 점에서 대리인 문제에 중점을 둔 기존의 OCIO 연구와 차별화된다(Shin and Lee, 2020; Yoon and Lee, 2019). 본 논문의 결과는 기금형 퇴직연금제도의 도입에 따른 OCIO 시장의 변화에 대해 몇 가지 정책적 함의를 갖는다. 첫째, $\mathrm{OCIO}$ 체계가 시장의 성장에서 중요한 부분일 수 있다. 둘째, 전담조직을 구성하여 운용하는 현재의 OCIO 체계에서는 기금형 퇴직연금 제도의 도입이 OCIO 시장 규모의 성장으로 이어지기 어려울 수 있다. 셋째, 기금형 퇴직연금 제도의 도입이 시장의 성장으로 이어지기 위해서는 국내 OCIO 체계가 소규모의 기금을 하나로 묶어 총괄적으로 관리하는 형태로 변화할 필요가 있을 수 있다.

본 연구의 구성은 다음과 같다. 제 2 장에서는 관련 선행연구를 정리하고 연구의 동기를 설명한다. 제 3 장에서는 모형을 설계하고 분석한다. 제 4 장에서는 모형을 통해 분석한 결과를 바탕으로 국내 $\mathrm{OCIO}$ 시장에 대한 정책 함의를 제시한다. 마지막으로 제 5 장에서는 분석내용을 요약하고 결론을 제시한다.

\section{2. 선행연구 및 연구의 동기}

최근 $\mathrm{OCIO}$ 에 관한 정부 및 학계와 업계의 관심이 증가하고 있으나, 이에 관한 심층적인 학술연구는 매우 부족하다. $\mathrm{OCIO}$ 의 개념과 현황에 관해 검토한 논문은 다음과 같다. Clark and Urwin(2017)은 OCIO의 개념을 정리하고, 투자에 대한 정보량과 전문성에 따라 기금의 유형을 분류한다. Shin et al.(2020)은 국내 OCIO 현황을 개괄적으로 검토한다. 이들은 해외 $\mathrm{OCIO}$ 와 비교하여 국내 $\mathrm{OCIO}$ 시장을 미성숙한 초기 단계로 정의하고, 국내 $\mathrm{OCIO}$ 시장의 특성을 검토하기 위해 $\mathrm{OCIO}$ 시장에 대한 $\mathrm{OCIO}$ 의 수요자인 기금과 공급자인 운용사 및 증권사의 인식을 설문으로 조사한다. 이들은 기금과 운용사 모두 수익률과 위험관리를 $\mathrm{OCIO}$ 의 중요한 요소로 인식하고 있음을 확인한다.

$\mathrm{OCIO}$ 시장을 이론적으로 분석한 논문도 존재하지만, 기존의 $\mathrm{OCIO}$ 에 관한 논의는 $\mathrm{OCIO}$ 의 대리인 문제에 초점을 맞추고 있다. Won(2006)은 행동경제학 관점에서 위험회피성향 변화에 따라 연기금의 포트폴리오 조정을 분석하여 채권 선호도가 나타남을 보인다. Shin and Lee(2020) 또한 행동경제학 관점에서 $\mathrm{OCIO}$ 의 낮은 수익률을 분석한다. OCIO가 손실회피(loss aversion) 성향을 보인다는 가정하에, 평가 기간이 짧은 것이 국내 OCIO가 수익률을 낮게 유지하는 원인이라 
한국증권학회지 제 50 권 5 호 (2021)

주장한다. 이들은 전망이론(prospect theory)을 통해 도출한 적정 평가 기간과 비교하여, 실제 OCIO의 평가 기간이 짧음을 보인다. Yoon and Lee(2019)는 OCIO의 보수체계를 이론모형으로 구성하고 이를 바탕으로 최적화 문제를 풀어 $\mathrm{OCIO}$ 의 대리인 문제를 분석하고, 대리인 문제를 해결하기 위해서는 $\mathrm{OCIO}$ 에 지급되는 성과보수의 비중이 커야 한다고 주장한다.

이러한 주장은 $\mathrm{OCIO}$ 보다 포괄적인 개념인 위탁자산운용에 관한 논의와 관련이 있다. Jensen (1968)의 연구 이후, 위탁자산운용 연구에서 대리인 문제는 중요한 위치를 차지하고 있다. 많은 연구가 자산을 위탁하는 과정에서 운용성과가 악화된다는 점을 실증적으로 보인다(Bergstresser et al., 2009; Chen et al., 2013; Guercio and Reuter, 2014; Jenkinson et al., 2016; Stoughton et al., 2011). 이러한 분석은 위탁운용에서 구조적인 비효율성이 나타남을 보이며, 그 원인으로 운용비용(Blake et al., 1993; Cho, 2014; Elton et al., 1993)과 보수구조(Cuoco and Kaniel, 2011; Kyle et al., 2011; Li and Tiwari, 2009; Ma et al., 2019; Ou-Yang, 2003; Stoughton, 1993; Stracca, 2006)에 주목한다. 보수구조에 관한 기존 논의는 성과보수가 대리인 문제 해결의 필수적인 요소라고 주장한다. 그러나 성과보수를 지급하여 매니저가 수익성과를 개선하도록 하더라도 위험관리성과가 악화될 수 있다(Huang et al., 2011). Lee et al.(2019)의 연구는 성과보수가 매니저의 위험관리를 악화시킬 수 있음을 지적한다. Ryu and Park(2020)은 대리인 문제로 인하여, 기금이 단순히 $\mathrm{OCIO}$ 의 성과보수 비중을 늘리는 것은 위험관리성과를 악화시킬 수 있다고 주장한다. 계약 기간과 재계약 가능성을 고려한 수리적 모형을 구성하여 이를 체계적으로 설명한다.

현재까지 OCIO 시장을 체계적으로 분석한 연구는 드물며, 이론연구 또한 주로 대리인 문제에 관하여 초점을 맞추고 있다. 이러한 기존 연구는 기금이 $\mathrm{OCIO}$ 를 선정한 이후, $\mathrm{OCIO}$ 의 의사결정에 대한 분석을 시도하지만, 기금이 $\mathrm{OCIO}$ 를 선정하는 과정을 포괄하지는 못한다. 국내 $\mathrm{OCIO}$ 시장에서의 변화는 기금형 퇴직연금이 도입됨에 따라 $\mathrm{OCIO}$ 시장에 참가할 것으로 기대되는 소규모 기금의 의사결정에 영향을 받을 것이다. 이는 기존의 연구가 추후 국내 OCIO 시장의 변화를 충분히 설명하기 어렵다는 것을 의미한다. 이에 따라 본 논문에서는 기존의 연구와는 달리, OCIO 선정과정에서의 경쟁을 이론모형을 통해 분석함으로써 기금이 OCIO 서비스를 사용할 조건을 검토한다.

본 연구에서는 기금이 $\mathrm{OCIO}$ 를 선정하는 과정이 조달 경매의 형태를 띤다는 점에 착안하여 $\mathrm{OCIO}$ 선정게임을 조달 경매에 관한 모형으로 설계하고 분석한다. 조달 경매는 일반적으로 재화나 서비스를 판매하는 쪽이 경쟁하여 낙찰을 받는 경매 형태로, 주로 대규모 공공사업의 사업자 선정과정이 이에 해당한다. 국내 $\mathrm{OCIO}$ 의 선정과정은 일반적으로 조달 경매와 같은 과정을 통해 이루어진다. 조달 경매에서도 가격요소를 중심으로 낙찰자를 선정하는 모형에 대한 논의가 다양하게 진행되었다(Anton and Yao, 1992; Bernheim and Whinston, 1986). 가장 대표적인 형태는 가장 낮은 가격을 제시한 입찰자가 사업자로 낙찰받는 최저가격낙찰제도 이다. 이를 변형하여 균형을 도출하고 다른 형태의 경매와 비교하는 등의 방식을 통해 적합한 경매 모형에 관한 다양한 연구가 진행되고 있다(Kokott et al., 2019; Li et al., 2018; Paulsen et al., 2020). 
Competition in the Outsourced Chief Investment Officer Market

그러나 OCIO 사업자 선정은 가격에 해당하는 운용보수나 성과보수 이외에도 OCIO 서비스의 품질을 가늠할 수 있는 여러 평가 기준에 따라 진행된다. 따라서 가격요소에 한정한 경매 모형 으로는 충분히 설명하기 어렵다. 이와 관련하여 Che(1993)가 제안한 다차원 경매 모형은 OCIO

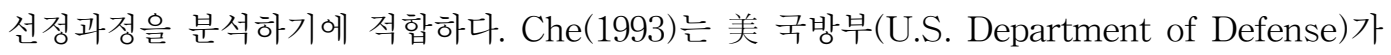
방위산업에 관한 조달을 경쟁입찰로 진행하는 사례를 분석하기 위해 다차원 경매 모형을 제안한다. 조달 경쟁에서 상품의 성능과 품질은 낙찰업체를 선정하는 중요한 기준이므로, 다차원 경매 모형에서는 가격요소 이외에도 품질 변수가 정의된다. 낙찰자 선정은 가격과 품질에 따라 도출된 평가점수를 바탕으로 이루어진다. Che(1993)의 연구 이후에는 가격요소 및 비가격요소를 모두 고려하여 낙찰자를 선정하는 다차원 경매에 대한 분석이 진행되었다. Asker and Cantillon(2008, 2010)은 품질 변수를 벡터(vector)로 정의함으로써 Che(1993)의 모형에 비해 더 다양한 평가항목을 포괄할 수 있는 방향으로 논의를 확장하였다. Chen(2021)은 구매자가 특정 기준에 따라 낙찰자와 계약하지 않을 수도 있다는 옵션을 추가하여 모형을 확장한다. Chen et al.(2011), Liu et al.(2012), Papakonstantinou and Bogetoft(2017)의 연구는 각각 특정한 비가격요소에 초점을 맞춰 다차원 조달 경매에 대한 이론적 모형을 구성하고 균형을 도출한다. 본 연구에서는 이러한 선행연구를 참고하여 다차원 경매 모형의 틀 하에서 OCIO 선정과정에서의 경쟁상황을 직관적으로 분석하고, 이를 토대로 정책시사점을 도출한다.

\section{3. 모형의 설계 및 분석}

본 절에서는 다차원 경매 모형을 응용하여 총 $M$ 개의 기금과 $N$ 개의 운용사가 OCIO 계약을 체결하는 상황을 분석한다. 개별 기금은 $F u n d_{m}, m=1,2, \ldots, M$, 으로 나타내며, 기금의 집합은 Fund $=\left\{\right.$ Fund $_{1}$, Fund $_{2}, \ldots$, Fund $\left._{M}\right\}$ 이다. 자산운용사의 집합은 Manager $=\left\{\right.$ Manager $_{0}$, Manager $_{1}$, Manager $_{2}, \ldots$, Manager $\left._{N}\right\}$ 이다. 개별 기금은 운용사 집합 중 하나를 자신의 OCIO로 선정한다. 즉, 개별 운용사 Manager $_{n}, n=1,2, \ldots, N$, 중 하나가 선정된다. 한편, $\mathrm{OCIO}$ 서비스를 사용하는 것이 이득이 되지 않을 경우, 기금은 $\mathrm{OCIO}$ 를 선정하지 않을 수 있다. 기금이 $\mathrm{OCIO}$ 를 선정하지 않는 경우, 기금은 운용사 집합에서 Manager $_{0}$ 을 선택하는 것으로 설정한다. 기금은 자산의 규모 순서로, 운용사는 운용역량이 큰 순서대로 정렬된다. 자산의 규모가 큰 순서대로 기금을 나열한다고 할 때, $m$ 번째 기금 $\left(F u n d_{m}\right)$ 의 자산규모는 $F_{m}$ 이다. 운용역량은 운용사가 동시에 운용할 수 있는 기금의 총 규모를 의미한다. 물론 현실에서는 운용역량을 정의할 때 기금의 규모뿐 아니라 기금의 수도 고려해야 할 것이다. 기금별로 위험선호도나 목표수익률, 투자 제약조건 등이 다르므로, 운용하는 기금의 수가 늘어나면 기금별 특성을 고려하여 별도로 기금을 관리해야 하고 추가적인 운용역량의 소진이 발생한다. 그러나 대형기금의 경우 일반적으로 분석자료의 요구 빈도와 수준이 높으므로, 기금 규모에 따라 운용사의 운용역량을 소진한다고 생각할 수 있다. 따라서, 본 연구에서는 운용사의 운용역량을 운용기금의 규모로 설정한다.

운용역량이 높은 순서대로 운용사를 정렬할 때, $n$ 번째 운용사 $\left(\right.$ Manager $\left._{n}\right)$ 의 운용역량은 $O_{n}$ 이다. 기금은 하나의 운용사와 계약을 체결하는 반면, 운용사는 자신의 운용역량 범위 내에서 여러 
한국증권학회지 제 50 권 5 호 (2021)

기금과 동시에 계약할 수 있다.7) 운용사는 운용 가능한 기금의 총 규모에서만 차이가 있고, 수익률과 위험에 대한 관리능력 등 OCIO 서비스의 품질은 모두 같다고 가정한다. 운용사는 자신의 운용역량에 따라, 규모가 큰 기금의 $\mathrm{OCIO}$ 선정 경쟁부터 참여한다.8) 예를 들어 운용사가 총 10 조 원의 자산을 운용할 수 있는 능력이 있고, 자산규모가 각각 11 조, 8 조, 3 조 원인 기금이 존재하는 상황을 가정하면 해당 운용사의 의사결정 과정은 다음과 같다. 자신의 운용역량을 넘어서는 11 조 원 규모의 기금에 대해서는 선정 경쟁에 참여하지 않으며, 8 조 규모의 OCIO 선정 경쟁에 참여한다. 8조 규모의 기금에 대한 $\mathrm{OCIO}$ 로 선정되면 남은 운용역량의 범위 내에서는 3 조 규모의 기금은 추가로 운용할 수 없다. 8조 규모의 기금에 대한 OCIO로 선정되지 않을 경우, 3 조 규모인 마지막 기금의 OCIO 선정 경쟁에 참여한다. 같은 상황에서 총 20조 원 규모의 자산을 운용할 수 있는 운용사의 경우, 11 조 규모의 첫 번째 기금의 OCIO 선정 경쟁에 참여하고, 다음으로 두 번째, 세 번째 기금의 입찰에 참여할지를 결정한다. 첫 번째(11조 규모)와 두 번째(8조 규모)의 기금에서 모두 OCIO로 선정될 경우, 세 번째 기금부터는 운용역량을 넘어서므로 입찰에 참여하지 않는다.

각각의 기금이 $\mathrm{OCIO}$ 를 선정하는 과정은 게임이론에서의 경매 형태를 보인다. 어떤 기금이 $\mathrm{OCIO}$ 를 선정한다고 할 때, 다수의 운용사가 해당 기금의 규모를 고려하여 비용을 책정하고, 이를 바탕으로 운용보수를 제시한다.9) 기금은 경매에 참여한 운용사 중 하나를 선택하거나 $\mathrm{OCIO}$ 서비스를 사용하지 않을 수 있다. 즉, $\mathrm{OCIO}_{m}$ 을 $\mathrm{Fund}_{m}$ 이 선정한 $\mathrm{OCIO}$ 라고 할 때, $O C I O_{m} \in$ Manager 이다. Manager ${ }_{n}$ 이 제시한 운용보수를 $\alpha_{n}$ 이라고 할 때, $m$ 번째 기금 $\left(\right.$ Fund $\left._{m}\right)$ 이 어떤 운용사를 $\mathrm{OCIO}$ 로 선택하느냐에 따라 운용보수가 결정된다. $O C I O_{m}$ 에 대한 운용보수의 함수를 $\alpha:$ Manager $\rightarrow[0,1]$ 이라고 할 때, $\alpha\left(\right.$ Manager $\left._{n}\right)=\alpha_{n}, n=0, \ldots, N$ 이다. 이때, OCIO를

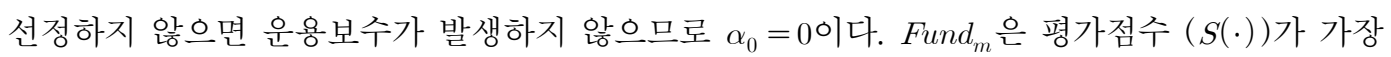

7) 하나의 운용사가 여러 기금과 OCIO 계약을 체결할 수 있고, 기금의 수 $(M)$ 가 운용사의 수 $(N)$ 보다 크다는 가정은 일반적이다. 특히, 본 연구에서는 기금형 퇴직연금이 도입되어 많은 수의 소규모 민간기금이 $\mathrm{OCIO}$ 서비스 사용을 검토하는 상황을 분석하므로, $M$ 이 충분히 큰 값을 갖는다고 볼 수 있다. 물론 기금이 여러 운용사와 OCIO 계약을 체결하는 사례도 존재한다. 주택도시기금이 미래에셋자산운용과 $\mathrm{NH}$ 투자증권을 복수 주간운용사로 하는 $\mathrm{OCIO}$ 체계를 구성하고 있는 것이 이에 해당한다. 그러나 복수 주간운용사를 선정한 $\mathrm{OCIO}$ 체계는 자산의 종류에 따라 주간운용사를 별도로 선정하는 것이 일반적이다. 이는 기금의 전략적 의사결정에 미치는 영향이 크기 때문인데, 이러한 복수 주간운용사 사례는 전략적 의사결정까지 전부 위임하는 엄밀한 의미의 OCIO 체계와는 다소 거리가 있는 형태라고 볼 수 있다. 따라서 본 논문에서는 기금이 자산 전체를 하나의 OCIO에 일임하는 형태만 고려한다.

8) 현실에서는 입찰 순서가 개별 기금의 계약 만료시기에 따라 다를 수 있다. 그러나, 일반적으로 운용사는 규모가 큰 기금의 $\mathrm{OCIO}$ 로 선정되는 것을 선호하므로 규모가 큰 기금에 대한 OCIO 선정 경쟁부터 고려할 것이다.

9) 본 연구에서는 국내 OCIO 시장에서 운용보수의 비중이 높다는 점을 고려하여 OCIO 서비스의 가격요소로 운용보수만을 고려한다. 운용보수만 고려할 경우, 경매의 입찰자인 운용사는 기금의 크기와 운용보수의 크기를 바탕으로 $\mathrm{OCIO}$ 사업자로 선정되면 얻을 수 있는 수익을 정확히 파악할 수 있으며, 자신의 운용역량에 따라 서로 다른 비용이 발생한다. 운용사들은 같은 OCIO 서비스로 경쟁하지만, 상품의 가치에 불확실 요소가 없으며, 상품의 가치가 자신의 운용역량에 따라 달라진다. 이러한 점은 OCIO 선정 경매가 공통가치경매(common value auction)보다는 독립가치경매(independent value auction)에 해당함을 의미한다. 
Competition in the Outsourced Chief Investment Officer Market

높은 운용사를 $O C I O_{m}$ 로 선정한다. 운용사가 제시하는 OCIO 서비스의 품질은 운용역량에 따라 서로 다르다고 가정한다. $n$ 번째 운용사의 서비스 품질이 $q_{n}$ 이고, $q_{1}>\ldots>q_{n}>q_{0}$ 이 성립한다. $q_{0}$ 은 $\mathrm{OCIO}$ 를 선정하지 않았을 때의 서비스 품질이므로, 기금이 자산을 직접 운용하는 경우의 효용을 의미한다. $O C I O_{m}$ 에 대한 서비스 품질의 함수를 $q: M a n a g e r \rightarrow\left[q_{0}, 1\right]$ 이라고 할 때, $q\left(\right.$ Manger $\left._{n}\right)=q_{n}$, for $n=0, \ldots, N$ 이다. 이러한 가정은 다차원 경매 모형에 관한 선행연구의 핵심적인 결과를 반영한다. Che(1993)와 Asker and Cantillon(2008)은 입찰자가 선택하는 최적의 품질이 비용에 관한 모수에 따라 결정된다는 사실을 보인다. 본 연구에서는 이러한 결과를 반영하여 운용사의 비용 모수에 해당하는 운용역량에 따라 서비스의 품질이 결정된다는 사실을 가정한 것이다.

$m$ 번째 기금 $\left(F_{n n d}\right)$ 은 식 (1)과 같이 평가점수 $\left(S\left(O C I O_{m}\right)\right)$ 를 극대화할 수 있는 운용사를 $\mathrm{OCIO}$ 로 선정한다.

$$
\max _{O C O_{m}} S\left(O C I O_{m}\right)=q\left(O C I O_{m}\right)-\alpha\left(O C I O_{m}\right)
$$

$m$ 번째 기금 $\mathrm{Fund}_{m}$ 의 $\mathrm{OCIO}$ 선정 경매에서 각각의 운용사는 자신의 비용 $C_{n}$ 을 고려하여 운용보수 $\alpha_{n}$ 과 서비스 품질 $q_{n}$ 을 제시한다. $n$ 번째 운용사 $\left(\right.$ Manager $\left._{n}\right)$ 에 대한 평가점수를 $s_{n}=S\left(\right.$ Manager $\left._{n}\right)=q_{n}-\alpha_{n}$ 이라고 할 때, $s_{n}$ 을 제외한 다른 평가점수 중 가장 높은 값인 $s_{-n}=\max \left[s_{0}, \ldots, s_{n-1}, s_{n+1}, \ldots, s_{N}\right]$ 보다 $s_{n}$ 이 클 경우, Manager ${ }_{n}$ 이 OCIO로 선정되며, 운용 규모인 $F_{m}$ 에 자신의 운용보수인 $\alpha_{n}$ 을 곱한 만큼의 금액을 받는다. 그리고 운용에 따른 비용으로 $C_{n}$ 이 발생한다. 가장 높은 평가점수를 받은 운용사가 총 $k$ 개 존재할 경우, 그 운용사들은 같은 평가점수를 받는다. 본 연구에서는 기금이 해당 운용사 중 하나를 무작위로 선정한다고 가정한다. 이에 따라 운용사가 기대할 수 있는 이윤은 $\mathrm{OCIO}$ 로 선정됐을 때 얻을 수 있는 이윤인 $\alpha_{n} F_{m}-C_{n}$ 을 $k$ 로 나눈 값이다. 마지막으로 어떤 다른 운용사가 자신보다 높은 평가점수를 받을 경우, OCIO로 선정될 수 없으므로 이윤은 0이 된다. 이에 따라 Manager $_{n}$ 의 이윤 극대화 문제는 식 (2)와 같다.

$$
\max _{\alpha_{n}, q_{n}} \pi_{n}=\left\{\begin{array}{cl}
\alpha_{n} F_{m}-C_{n}, & \text { if } s_{n}>s_{-n} \\
\frac{1}{k}\left(\alpha_{n} F_{m}-C_{n}\right), & \text { if } s_{n}=s_{-n} . \\
0, & \text { if } s_{n}<s_{-n}
\end{array}\right.
$$

본 연구에서는 운용방식에 따라 운용비용에 대한 가정을 두 경우로 나누어 분석한다. 첫 번째 운용방식은 $\mathrm{OCIO}$ 가 기금별로 전담조직을 구성하여 운용하는 경우이다. 운용사가 규모가 작은 기금을 운용하더라도, 전담조직을 구성하기 위해서는 일정수준 이상의 비용이 발생한다. 따라서 큰 기금일수록 기금의 규모 대비 비용의 크기가 줄어든다. 따라서 운용사는 총 기금의 규모에 대한 운용비용의 함수를 $f$ 라고 할 때, 첫 번째 운용방식에서 Manager $_{n}$ 의 비용은 식 (3)과 같이 정의할 수 있다. 


$$
C_{n}=f\left(F_{m}\right) \cdot F_{m} \text {, where } f^{\prime}<0
$$

두 번째 운용방식은 OCIO가 다수의 기금을 총괄적으로 운용하는 경우이다. 첫 번째 운용방식과 달리 기금별로 전담조직을 구성할 필요 없이 운용사가 전체 자산에 대한 관리조직을 구성하면 되므로 운용역량이 큰 $\mathrm{OCIO}$ 일수록 운용에 따른 비용이 낮다. 식 (4)에서와 다르게 두 번째 운용방식에서는 운용사가 운용하는 전체 기금에 대해 운용조직을 구성하므로 운용하는 기금의 총 규모 대비 비용이 운용역량인 $O_{n}$ 에 따라 결정된다. 이에 따라 두 번째 운용방식에서 Manager $_{n}$ 의 비용은 식 (4)와 같이 정의할 수 있다.10)

$$
C_{n}=f\left(O_{n}\right) \cdot F_{m}, \text { where } f^{\prime}<0
$$

운용역량에 따라 운용사의 서비스 품질이 서로 다르므로 운용역량의 공개 여부가 개별 운용사의 전략 결정에 영향을 미칠 수 있다. 따라서 각 운용사가 경쟁사의 운용역량을 모를 때에 대한 분석이 필요하다. 따라서 본 연구에서는 총 네 가지 형태의 경매 게임을 구성하여 분석을 진행한다. 기금별로 전담조직을 구성하는 첫 번째 운용방식과 OCIO가 총괄적으로 자산을 관리하는 두 번째 운용방식에 대해 각각 운용역량이 공개되는 경우와 그렇지 않은 경우를 나눠 분석한다. 총 네 번의 경매 게임에서 개별 기금의 OCIO 선정과정을 분석하여 내쉬균형(Nash equilibrium)을 도출한 뒤, 기금의 규모에 따라 OCIO 선정이 순차적으로 이루어지는 상황의 균형을 분석한다. 이때의 내쉬균형은 게임에 참여한 모든 경기자(player)가 자신의 전략(strategy)을 바꿀 유인이 없는 균형상황을 의미한다.

우선 기금별로 전담조직을 구성하는 경우를 분석하면 다음과 같다. 이때, 운용사는 모두 OCIO로 선정되었을 때, $f\left(F_{m}\right) \cdot F_{m}$ 의 비용이 발생한다. 운용역량을 서로 알고 있을 때, 서비스 품질이 가장 높은 첫 번째 운용사 $\left(\right.$ Manager $\left._{1}\right)$ 가 $f\left(F_{m}\right)+\left(q_{1}-q_{2}\right)$ 보다 조금 작은 수준으로 운용보수 $\alpha_{1}$ 을 제시하고, 다른 모든 운용사 $\left(\right.$ Manager $\left._{n}, n=2, \ldots, N\right)$ 가 $f\left(F_{m}\right)$ 만큼을 운용보수로 제시하는 경우가 내쉬균형이 될 수 있다. Manager $r_{1}$ 의 입장에서는 $\alpha_{1}<f\left(F_{m}\right)$ 인 경우, $\mathrm{OCIO}$ 로 선정되지만, 손해를 보게 되고, $\alpha_{1} \geqq f\left(F_{m}\right)+\left(q_{1}-q_{2}\right)$ 인 경우, 두 번째 운용사 $\left(\right.$ Manager $\left._{2}\right)$ 가 OCIO로 선정될 위험이 있다. $f\left(F_{m}\right) \leqq \alpha_{1}<f\left(F_{m}\right)+\left(q_{1}-q_{2}\right)$ 인 경우, $\mathrm{OCIO}$ 로 선정되므로, Manager ${ }_{1}$ 은 이 중 가장 높은 이윤을 낼 수 있는 $f\left(F_{m}\right)+\left(q_{1}-q_{2}\right)-\epsilon$ 만큼의 운용보수를 제시한다. 다른 운용사의 경우,

10) 현실적으로 두 운용방식의 비용은 기금의 규모 $\left(F_{m}\right)$ 과 운용역량 $\left(O_{n}\right)$ 의 영향을 모두 받을 수 있다. 예를 들어, 전담운용조직을 요구하더라도 역시 운용사의 운용역량 및 경험이 증가할수록 전반적인 비용은 줄어 수 있다. 전담운용조직을 요구하지 않더라도, 기금의 규모가 클 경우, 규모의 경제로 인해 전체 규모 대비 비용의 크기는 줄어들 것으로 생각할 수 있다. 그러나 운용방식별로 각 결정요인의 영향에 차이가 있다. 전담운용조직을 구성하는 경우, 기금의 규모가 운용역량보다 비용에 미치는 영향이 클 것이고, 전담운용조직을 구성하지 않는 경우, 운용역량이 비용이 미치는 영향이 기금의 규모보다 클 것이다. 기금의 규모와 운용역량이 비용에 미치는 영향이 달라지더라도 핵심적인 결론은 바뀌지 않으므로, 본 연구에서는 분석의 단순화를 위해 운용방식별로 하나의 결정요인이 비용에 영향을 미친다고 가정한다. 
$\alpha_{n}<f\left(F_{m}\right)$ 인 경우, $\mathrm{OCIO}$ 로 선정되더라도 손해를 보고, $\alpha_{n}>f\left(F_{m}\right)$ 인 경우, $\mathrm{OCIO}$ 로 선정되지 못한다. 따라서 운용역량이 높은 소수의 운용사가 OCIO 시장을 독과점한다.

다음으로 운용역량이 공개되지 않은 상황에서 기금별 전담조직을 구성하는 경우를 분석하면 다음과 같다. 운용역량이 높을수록 서비스 품질이 높으므로, 개별 운용사가 다른 운용사의 서비스 품질이 균등분포를 따른다고 믿는다 $\left(q_{n} \sim\right.$ i.i.d.Uniform $\left.\left.\left[q_{0}, 1\right]\right) .11\right)$ 운용사의 운용보수는 자신의 서비스 품질에 따라 결정된다 $\left(\alpha_{n}=B\left(q_{n}\right)\right)$. 이때, 강한 단조함수(strictly monotonic function)인 $B$ 는 개별 운용사의 최적반응함수로 모든 운용사에 대해 동일하다고 가정한다. $n$ 번째 개별 운용사 $\left(\right.$ Manager $\left._{n}\right)$ 의 평가점수 $\left(q_{n}-\alpha_{n}\right)$ 가 다른 운용사보다 클 때 $\mathrm{OCIO}$ 로 선정되어, Manager 은 $^{2}$ $\alpha_{n}-f\left(F_{m}\right)$ 의 이윤을 얻는다. 이에 따라 Manager $_{n}$ 의 기대이윤함수를 정리하면 식 (5)와 같다.

$$
\max _{\alpha_{n}} E\left[\pi_{n}\right]=\left\{\alpha_{n}-f\left(F_{m}\right)\right\} F_{m} \cdot \operatorname{Pr}\left[q_{n}-\alpha_{n}>q_{-n}-\alpha_{-n}\right]
$$

Manager $_{n}$ 에 대한 평가점수 $\left(q_{n}-\alpha_{n}\right)$ 가 다른 모든 운용사에 대한 평가점수보다 클 확률인 $\operatorname{Pr}\left[q_{n}-\alpha_{n}>q_{-n}-B\left(q_{-n}\right)\right]$ 을 계산하면 식 (6)과 같다. 각 운용사의 수익률이 독립적이고 동일하게 분포되어있다고 가정하였으므로, Manager $_{n}$ 이 가장 높은 평가점수를 받을 확률은 $\alpha_{n}$ 이 다른 운용사 $\left(\right.$ Manager $\left._{l}, l \neq n\right)$ 가 받은 평가점수 $\left(q_{l}-B\left(q_{l}\right)\right)$ 보다 높을 확률의 곱으로 정리할 수 있다.

$$
\begin{aligned}
\operatorname{Pr}\left[q_{n}-\alpha_{n}>q_{-n}-B\left(q_{-n}\right)\right] & \\
= & \operatorname{Pr}\left[q_{n}-\alpha_{n}>q_{1}-B\left(r_{1}\right)\right] \cdot \ldots \cdot \operatorname{Pr}\left[q_{n}-\alpha_{n}>q_{n-1}-B\left(q_{n-1}\right)\right] \cdot \operatorname{Pr}\left[q_{n}-\alpha_{n}>q_{n+1}-B\left(q_{n+1}\right)\right] \cdot \ldots \\
& \ldots \cdot \operatorname{Pr}\left[q_{n}-\alpha_{n}>q_{N}-B\left(r_{N}\right)\right] \\
= & \operatorname{Pr}\left[q_{n}-\alpha_{n}>q_{l}-B\left(q_{l}\right)\right]^{N-1}
\end{aligned}
$$

$q_{n}-\alpha_{n}$ 이 다른 어떤 특정 운용사 $\left(\right.$ Manager $\left._{l}\right)$ 에 대한 평가점수 $\left(q_{l}-B\left(q_{l}\right)\right)$ 보다 높을 확률은 <그림 $1>$ 과 같이 계산할 수 있다. 이때, $C\left(q_{l}\right)=q_{l}-B\left(q_{l}\right)$ 이다.

따라서 Manager $_{n}$ 의 기대이윤 극대화 문제는 식 (7)과 같이 정리할 수 있다.

$$
\max _{\alpha_{n}} E\left[\pi_{n}\right]=\left\{\alpha_{n}-f\left(F_{m}\right)\right\} F_{m} \cdot\left[\frac{1}{1-q_{0}} \cdot\left\{C^{-1}\left(q_{n}-\alpha_{n}\right)-q_{0}\right\}\right]^{N-1}
$$

Manager $_{n}$ 은 식 (7)을 운용보수 $\alpha_{n}$ 에 대해 극대화한다. 식 (8)은 이를 위해 1계 조건을 계산한 것이다.

11) 본 연구에서는 Asker and Cantillon(2008, 2010), Che(1993), Chen(2021) 등 다차원 경매 모형에 관한 선행연구를 참고하여 운용역량과 같은 비용 모수의 분포가 상호 독립적으로 분포함을 가정한다. 그러나 선행연구에서 일반적인 함수로 정의하고 논의를 진행한 것과 달리, 본 연구에서는 구체적으로 균등분포를 가정한다. 이러한 분석은 직관적인 이해를 돕기 위한 것으로, 분석결과가 주는 함의에는 큰 영향을 주지 않는다. 


$$
\begin{aligned}
F . O . C .: & \frac{\partial E\left[\pi_{n}\right]}{\partial \alpha_{n}}=F_{m} \cdot\left[\frac{1}{1-q_{0}} \cdot\left\{C^{-1}\left(q_{n}-\alpha_{n}\right)-q_{0}\right\}\right]^{N-1} \\
& -\left\{\alpha_{n}-f\left(F_{m}\right)\right\} F_{m} \cdot(N-1)\left[\frac{1}{1-q_{0}} \cdot\left\{C^{-1}\left(q_{n}-\alpha_{n}\right)-q_{0}\right\}\right]^{N-2} \cdot \frac{1}{1-q_{0}} \cdot \frac{d C^{-1}\left(q_{n}-\alpha_{n}\right)}{d \alpha_{n}}=0
\end{aligned}
$$

최적반응함수 $B$ 는 모든 운용사에 대하여 대칭적이며, $\alpha_{n}=B\left(q_{n}\right)$ 이다. $\alpha_{n}=B\left(q_{n}\right)$ 를 식 (8)에 대입하여 정리하면, 식 (9)와 같다. ${ }^{12)}$

$$
\alpha_{n}=f\left(F_{m}\right)
$$

기금은 수익률이 높은 운용사를 선호하므로 운용보수를 모두 $f\left(F_{m}\right)$ 만큼 제시하게 되더라도 기금은 수익률이 가장 높은 운용사를 $\mathrm{OCIO}$ 로 선정한다는 점에서 시장 균형은 다르게 나타난다. 기금별로 전담조직을 구성하는 경우는 수익률의 차이가 발생하게 되었을 때, 독점 현상이 나타난다.

\section{〈그림 1〉어떤 운용사에 대한 평가점수가 다른 운용사보다 높을 확률}

아래 그림은 $n$ 번째 운용사에 대한 평가점수 $\left(q_{n}-\alpha_{n}\right)$ 가 $l$ 번째 운용사에 대한 평가점수 $\left(q_{l}-\alpha_{l}\right)$ 보다 높을 확률을 보여준다. $l$ 번째 운용사의 서비스 품질 $q_{l}$ 의 확률분포가 아래와 같을 때, $q_{n}-\alpha_{n}$ 이 $q_{l}-\alpha_{l}$ 보다 높을 확률은 빗금 친 영역의 넓이와 같다.

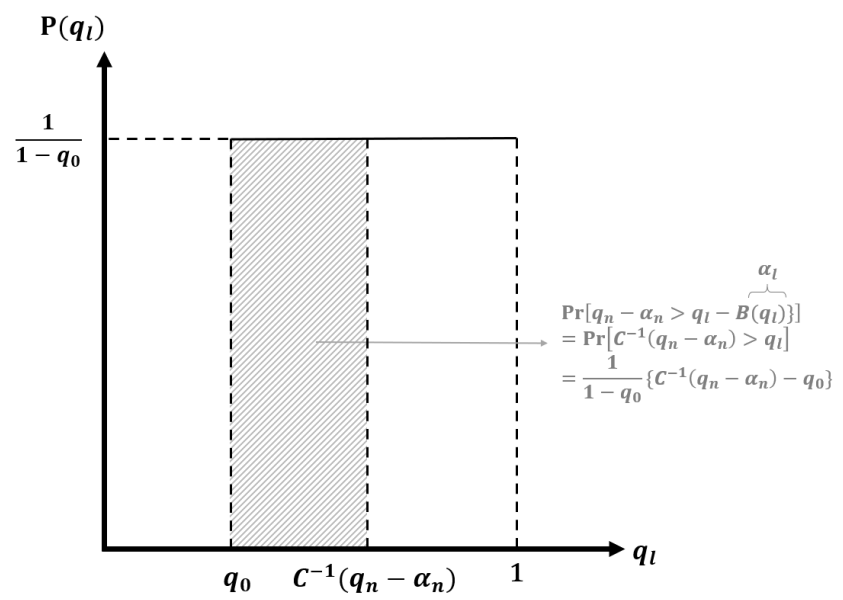

$\mathrm{OCIO}$ 가 총괄적으로 기금을 운용하는 경우, 운용사는 $\mathrm{OCIO}$ 로 선정되었을 때, 자신의 역량에 따라 $f\left(O_{n}\right) \cdot F_{m}$ 의 운용비용이 발생한다. 운용역량을 서로 알고 있는 경우, 수익률이 가장 높은 첫 번째 운용사 $\left(\right.$ Manager $\left._{1}\right)$ 가 $f\left(O_{2}\right)+\left(q_{1}-q_{2}\right)$ 보다 조금 작은 수준으로 운용보수를 제시하고, 다른 모든 운용사 Manager $\left._{n}, n=2, \ldots, N\right)$ 가 $f\left(O_{n}\right)$ 만큼을 운용보수로 제시하는 경우가 내쉬균형이 될 수 있다. Manager $r_{1}$ 은 $\alpha_{1}<f\left(O_{1}\right)$ 인 경우, $\mathrm{OCIO}$ 로 선정되지만, 손해를 보게 되고, $\alpha_{1} \geqq$

12) 식 (9)에 대한 자세한 도출방법은 Appendix A를 참고하시오. 
$f\left(O_{2}\right)+\left(q_{1}-q_{2}\right)$ 인 경우, 두 번째 운용사 $\left(\right.$ Manager $\left._{2}\right)$ 가 OCIO로 선정될 위험이 있다. $f\left(O_{1}\right) \leqq \alpha_{1}$ $<f\left(O_{2}\right)+\left(q_{1}-q_{2}\right)$ 인 경우, $\mathrm{OCIO}$ 로 선정되므로, Manager $_{1}$ 은 이 중 가장 큰 이윤을 낼 수 있는 $f\left(O_{2}\right)+\left(q_{1}-q_{2}\right)-\epsilon$ 만큼의 운용보수를 제시한다. 다른 운용사의 경우, $\alpha_{n}<f\left(O_{n}\right)$ 인 경우, $\mathrm{OCIO}$ 로 선정되더라도 손해를 보고, $\alpha_{n}>f\left(O_{n}\right)$ 인 경우, $\mathrm{OCIO}$ 로 선정되지 못한다.

운용사가 서로의 운용역량을 모르는 경우에 대한 분석은 다음과 같다. 전담조직을 구성하는 경우 마찬가지로 개별 운용사는 다른 운용사의 서비스 품질이 균등분포를 따른다고 믿는다 $\left(q_{n} \sim\right.$ i.i.d.Uniform $\left.\left[q_{0}, 1\right]\right)$. 운용사의 운용보수는 자신의 수익률에 따라 결정된다 $\left(\alpha_{n}=B\left(q_{n}\right)\right)$. 이때, $B$ 는 개별 운용사의 최적반응함수로 미분 가능하며, 모든 운용사에 대해 동일하고 단조 증가한다고 가정한다. $n$ 번째 개별 운용사 $\left(\right.$ Manager $\left._{n}\right)$ 는 자신의 평가점수 $\left(q_{n}-\alpha_{n}\right)$ 가 다른 운용사 들보다 클 경우 $\mathrm{OCIO}$ 로 선정되어 $\alpha_{n}-f\left(O_{n}\right)$ 의 이윤을 얻는다. 이에 따라 Manager $_{n}$ 의 기대이윤 함수를 정리하면 식 (10)과 같다.

$$
\max _{\alpha_{n}} E\left[\pi_{n}\right]=\left\{\alpha_{n}-f\left(O_{n}\right)\right\} F_{m} \cdot \operatorname{Pr}\left[q_{n}-\alpha_{n}>q_{-n}-\alpha_{-n}\right]
$$

Manager $_{n}$ 의 평가점수가 다른 모든 운용사의 평가점수보다 작을 확률인 $\operatorname{Pr}\left[q_{n}-\alpha_{n}>q_{-n}-B\left(q_{-n}\right)\right]$ 에 대한 계산은 이전과 같다. $f\left(O_{n}\right)$ 은 운용역량에 따른 비용을 의미하는데, 운용역량이 높을수록 낮은 값을 갖는다. 또한, 운용역량이 높을수록 수익률이 높다고 가정하므로, $f\left(O_{n}\right)$ 은 $q_{n}$ 에 대한 함수로 정리할 수 있다. 따라서 $f\left(O_{n}\right)=g\left(q_{n}\right)$ 이라고 정의한다. 서비스 품질이 높을수록 운용역량이 높다는 것을 의미하므로 $g$ 는 $q_{n}$ 에 대한 감소함수이므로, $g^{\prime}<0, g^{\prime \prime}>0$ 임을 가정한다.

따라서 Manager $_{n}$ 의 기대이윤 극대화 문제는 식 (11)과 같이 정리할 수 있다.

$$
\max _{\alpha_{n}} E\left[\pi_{n}\right]=\left\{\alpha_{n}-g\left(q_{n}\right)\right\} F_{m} \cdot\left[\frac{1}{1-q_{0}} \cdot\left\{C^{-1}\left(q_{n}-\alpha_{n}\right)-q_{0}\right\}\right]^{N-1}
$$

Manager $_{n}$ 은 식 (11)을 운용보수 $\alpha_{n}$ 에 대해 극대화한다. 식 (12)는 이를 위해 1계 조건을 계산한 것이다.

$$
\begin{aligned}
\text { F.O.C. }: & \frac{\partial E\left[\pi_{n}\right]}{\partial \alpha_{n}}=F_{m} \cdot\left[\frac{1}{1-q_{0}} \cdot\left\{C^{-1}\left(q_{n}-\alpha_{n}\right)-q_{0}\right\}\right]^{N-1} \\
& \left\{\alpha_{n}-g\left(q_{n}\right)\right\} F_{m} \cdot(N-1)\left[\frac{1}{1-q_{0}} \cdot\left\{C^{-1}\left(q_{n}-\alpha_{n}\right)-q_{0}\right\}\right]^{N-2} \\
& \cdot \frac{1}{1-q_{0}} \cdot \frac{d C^{-1}\left(q_{n}-\alpha_{n}\right)}{d \alpha_{n}}=0
\end{aligned}
$$

최적반응함수 $B$ 는 모든 운용사에 대하여 대칭적이며, $\alpha_{n}=B\left(q_{n}\right)$ 이다. $\alpha_{n}=B\left(q_{n}\right)$ 를 식 (12)에 대입하여 정리하면, 식 (13)과 같다.13)

13) 식 (13)에 대한 자세한 도출방법은 <Appendix B>를 참고하시오. 


$$
\alpha_{n}=g\left(q_{n}\right)+J\left(q_{n}\right), \text { where } J\left(q_{n}\right)=-\frac{1}{\left(q_{n}-q_{0}\right)^{N-1}} \int_{q_{0}}^{q_{n}} g^{\prime}(q) \cdot\left(q-q_{0}\right)^{N-1} d q
$$

식 (13)에서 $g\left(q_{n}\right)=f\left(O_{n}\right)$ 로 운용사의 비용을 나타낸다. $J(q)$ 는 정보 비대칭성에 따라 각 운용사가 자신의 비용을 감추는 정도를 나타내며, $g^{\prime}<0$ 이기 때문에 $J\left(q_{n}\right)$ 는 양의 값을 가진다. 즉, 운용사는 자신의 비용보다 조금 높은 수준의 운용보수를 제시한다. 식 (13)에서 $d \alpha_{n} / d q_{n}$ 을 계산하면 식 (14)와 같다. $g^{\prime}<0$ 이므로, 식 (14)에서 $d \alpha_{n} / d q_{n}<0$ 임을 확인할 수 있다.

$$
\frac{d \alpha_{n}}{d q_{n}}=(N-1) \frac{1}{\left(q_{n}-q_{0}\right)^{N}} \int_{q_{0}}^{q_{n}} g^{\prime}(q) \cdot\left(q-q_{0}\right)^{N-1} d q
$$

이는 서비스 품질과 운용역량이 높은 운용사일수록 낮은 운용보수를 제시한다는 것을 의미한다. 따라서 가장 높은 운용역량을 갖는 운용사가 $\mathrm{OCIO}$ 로 선정된다. 즉, 총괄적으로 기금을 운용하는 경우에도 전담조직을 구성하는 경우와 마찬가지로 운용역량이 높은 소수의 운용사가 시장을 독과점하게 된다.

하지만 운용방식에 따라 기금의 의사결정에는 차이가 생긴다. 이를 확인하기 위해 운용방식별로 $\mathrm{OCIO}$ 선정 경쟁이 반복되는 상황을 분석하면 다음과 같다. 운용방식과 무관하게 기금은 운용역량이 가장 높은 운용사를 $\mathrm{OCIO}$ 로 선정한다. 따라서 $\mathrm{OCIO}$ 시장의 균형은 비슷하게 나타난다. 하지만 운용방식에 따라 운용보수에 차이가 발생하기 때문에 기금의 규모가 일정 수준 이하인 기금은 $\mathrm{OCIO}$ 를 선정하지 않을 수 있다. 기금이 OCIO를 선정하지 않고 스스로 자산을 관리할 경우 운용보수는 발생하지 않고 $q_{0}$ 만큼의 효용을 얻는다고 할 때, 기금은 $\mathrm{OCIO}$ 의 평가점수가 $q_{0}$ 보다 클 경우에만 $\mathrm{OCIO}$ 를 선정한다. 운용사들의 운용역량이 공개되어있다고 가정할 때, 전담조직을 구성할 경우와 총괄 운용하는 경우의 평가점수를 각각 $s_{1}, s_{2}$ 라고 하면 $s_{1}=q_{2}-f\left(F_{m}\right)+\epsilon$ 과 $s_{2}=q_{2}-f\left(O_{1}\right)+\epsilon$ 이다. 기금의 자산규모가 작을수록 $f\left(F_{m}\right)$ 은 큰 값을 가지므로, 규모가 일정수준 이하인 기금에 대해서는 $s_{1}<q_{0}$ 가 성립할 수 있다. 즉, 규모가 작은 기금은 전담조직을 구성하는 경우 OCIO 서비스의 품질에 비해 높은 비용을 지급해야 하므로 $\mathrm{OCIO}$ 서비스를 사용하지 않는다. 이에 따라 전담조직을 구성하는 경우에는 OCIO 시장의 균형이 <그림 2>의 Panel A와 같은 형태로 연결된다. 반면, OCIO가 기금을 총괄적으로 운용할 때는 평가점수 $q_{0}$ 보다 낮게 나오기 어렵다. $s_{2}<q_{0}$ 은 운용사의 운용역량이 작거나 서비스의 품질이 낮다는 것을 의미하는데, 이 경우 운용사는 OCIO 시장에 진입할 수 없다. 따라서 시장에 진입한 운용사에 대해서는 항상 $q_{0}<s_{2}$ 의 관계가 성립한다. 이에 따라 총괄 운용하는 경우 OCIO 시장의 균형은 <그림 $2>$ 의 Panel B와 같다. 운용역량이 공개되어있지 않은 경우, 전담조직을 구성하는 경우와 총괄 운용하는 경우의 평가점수는 각각 $s_{1}=q_{1}-f\left(F_{m}\right), s_{2}=q_{1}-f\left(O_{1}\right)-J\left(q_{1}\right)$ 이다. 기금의 자산규모가 충분히 작은 기금에 대해 $s_{1}<q_{0}<s_{2}$ 가 성립할 수 있으므로, 운용역량이 공개된 경우와 동일한 균형이 도출된다.

$\mathrm{OCIO}$ 서비스 품질의 차이로 인하여 기금은 운용능력이 높은 운용사를 선호하게 되고, 이에 따라 운용방식과 무관하게 운용역량이 높은 운용사들이 시장을 지배하게 된다. 반면, 서비스 
Competition in the Outsourced Chief Investment Officer Market

품질에 차이가 발생하더라도, OCIO가 총괄적으로 기금을 운용하는 경우는 비용상의 이점으로 인해 모든 기금이 OCIO 서비스를 사용할 수 있지만, 기금별 전담조직을 구성하는 경우에는 규모가 작은 기금이 $\mathrm{OCIO}$ 서비스를 사용하지 않게 될 수 있다. 서비스 품질의 차이를 고려하여 모형을 보다 현실적으로 확장할 경우, 전담조직을 구성하는 방식의 OCIO 체계가 기금의 OCIO 서비스 사용을 제한할 뿐만 아니라 OCIO 공급자의 독과점 형태가 나타날 수 있음을 보여준다.

\section{4. 정책 함의}

$\mathrm{OCIO}$ 가 기금을 운용하는 방식에 따라 수요와 공급에 미치는 영향에 차이가 생긴다. 기금별로 전담조직을 구성하는 경우, 소규모의 기금은 $\mathrm{OCIO}$ 서비스를 사용할 유인이 적다. 반면, OCIO 공급은 경쟁적인 형태를 띨 것이다. 반면, $\mathrm{OCIO}$ 가 여러 기금을 총괄적으로 관리할 경우, 운용역량이 높은 소수의 운용사가 $\mathrm{OCIO}$ 서비스의 상당한 부분을 공급하게 된다. 즉, 소수 $\mathrm{OCIO}$ 가 시장을 독과점하는 형태가 나타날 수도 있다. OCIO가 소규모의 기금에 대해서도 낮은 운용보수로 서비스를 제공할 수 있으므로 소규모 기금도 OCIO 서비스를 사용할 수 있게 되는 장점도 있다. 이러한 함의는 가정을 완화하여 각 운용사가 운용능력에 따라 다른 서비스 품질을 제공한다고 가정하더라도 유사하지만, 운용사의 서비스 품질이 모두 같은 경우보다 특정 운용사가 시장을 독과점 하는 형태가 나타날 가능성이 크다.

이러한 분석결과는 기금형 퇴직연금 제도가 도입되더라도 OCIO가 기금을 운용하는 방식에 따라 OCIO 시장 규모의 증가가 크지 않을 수 있음을 시사한다. 소규모의 기금이 OCIO에게 전담조직 구성을 요구할 경우, $\mathrm{OCIO}$ 가 비용부담으로 인해 높은 운용보수를 제시하게 될 가능성이 크다. 그러나 현실적으로는 기금이 상황에 따라 운용방식을 선택하게 될 가능성이 크다. 지금까지의 논의에서는 기금들이 모두 하나의 운용방식을 선택하는 경우 시장 균형을 분석하였다. 이러한 분석결과를 바탕으로 기금이 운용방식을 선택할 수 있는 경우에 대해서도 추론할 수

\section{〈그림 2〉 운용방식에 따른 $\mathrm{OCIO}$ 시장의 균형}

아래 그림은 운용방식에 따른 $\mathrm{OCIO}$ 시장의 균형을 도식화한 것이다. Panel A는 기금별로 전담조직을 구성하는 경우를 보여주며, Panel B는 OCIO가 총괄적으로 기금을 관리하는 경우를 보여준다. Fund o $_{m}$ 기금을, Manager ${ }_{n}$ 은 운용사를 의미한다. 점선은 기금과 운용사가 상호 $\mathrm{OCIO}$ 계약을 체결함을 의미한다.

Panel A: 전담조직 구성

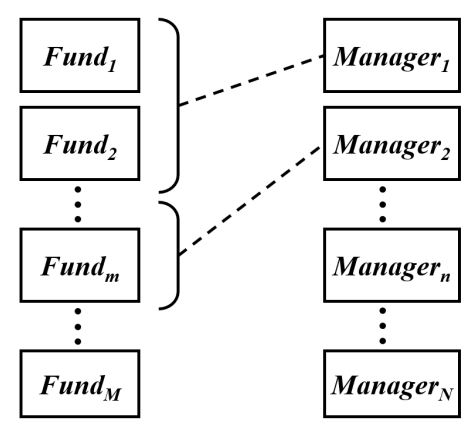

Panel $\mathrm{B}$ : 총괄적 운용

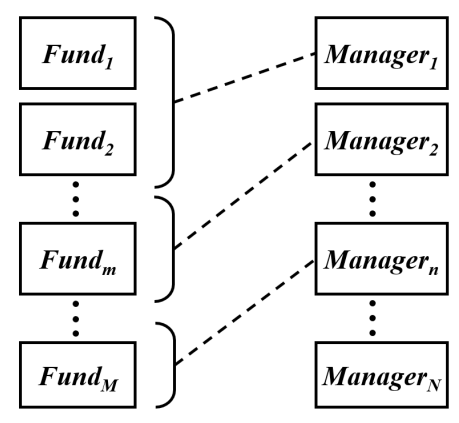


있다. 앞서 논의한 바와 같이 기금의 규모가 일정수준 이하이면 $\left(q_{0}<f\left(F_{m}\right)\right)$ 기금은 전담조직을 구성하는 방식으로는 OCIO 서비스를 사용하지 않는다. 따라서 규모가 작은 기업의 경우에는 총괄적으로 운영하는 방식을 $\mathrm{OCIO}$ 에게 요구할 수 있다. 즉, 기금이 OCIO 운영방식을 선택할 수 있는 경우 시장 균형은 다음 <그림 3>과 같다.

$<$ 그림 3>에서와 같이 규모가 큰 기금은 OCIO에게 더 많은 영향력을 미칠 수 있는 전담조직 구성을 요구하고, 규모가 작은 기금은 낮은 비용으로 OCIO 서비스를 이용하기 위해 총괄적으로 기금을 운용할 것을 요구한다. 이는 모든 기금이 OCIO 서비스를 사용할 수 있는 균형에 해당하지만, 규모가 작은 기금은 수익률이 낮은 운용사를 OCIO로 선정하게 됨을 알 수 있다. 추후 기금형 퇴직연금이 도입되어 소규모 민간기금의 수가 늘어나게 되더라도 소규모 기금들이 총괄적 운영을 요구하는 형태로 시장 규모가 커질 수 있을 것으로 보인다.

현재 국내 OCIO 시장은 기금별로 전담조직을 구성하는 첫 번째 운용방식에 가깝다. 대형기금을 중심으로 $\mathrm{OCIO}$ 서비스를 사용하고 있으며, 이들은 전담조직 신설을 $\mathrm{OCIO}$ 에게 요구하고 있다. 이는 해외 OCIO가 다수의 기업연금에 대한 총괄관리를 제공하는 것과 다른 모습을 보인다. 국내 $\mathrm{OCIO}$ 시장이 충분히 성장하기 위해서는 전담조직 구성을 중심으로 하는 현재의 OCIO 시장 구조가 개선되어야 한다. 이를 위해서는 민간기금을 펀드의 펀드(fund of funds) 형태로 구성하는 방안을 고려할 수 있다. 이 경우, 소규모 기금들을 모아 하나의 큰 기금이 만들어지므로, 기금별 전담조직을 구성할 때 발생하는 비용부담을 줄일 수 있다. 이는 금융위원회가 도입한 민간 연기금 투자풀 제도를 활용하는 것에 해당한다.

〈그림 3〉기금이 운영방식을 선택할 때, OCIO 시장 균형

아래 그림은 기금이 OCIO 운영방식을 선택할 수 있는 경우의 시장 균형을 도식화한 것이다. Fund 은 기금을, Manager ${ }_{n}$ 은 운용사를 의미한다. 실선은 전담조직을 구성하는 방식으로, 점선은 총괄적으로 운영하는 방식으로 $\mathrm{OCIO}$ 계약을 체결함을 의미한다.

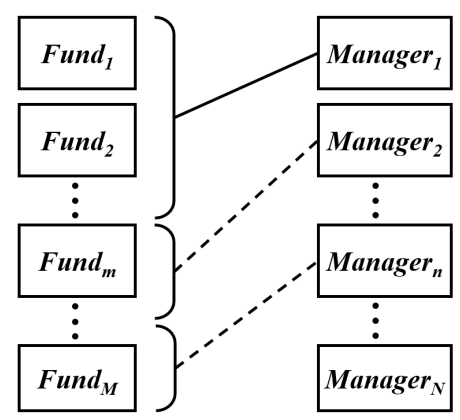

민간 연기금 투자풀은 한국투자신탁운용을 주간운용사로 하는 OCIO 체계를 구성하고 있다. 이는 기획재정부의 공적 연기금 투자풀과 마찬가지로 여러 민간 연기금을 모아 투자풀을 형성하고 운용하는 형태로, 규모의 경제를 실현하여 운용 효율성을 개선할 수 있다는 장점이 있다. 하지만 특정 기관이 주도하여 투자풀을 구성하면, 이는 하나의 대형기금이 새로 생기는 것과 같다. 민간 연기금의 수가 늘어날수록 민간 연기금 투자풀의 규모가 증가하기 때문에 운용역량이 
충분히 큰 운용사가 아니라면 민간 연기금 투자풀의 OCIO로 선정되기 어렵다. 앞서 분석한 바와 같이 $\mathrm{OCIO}$ 시장은 소수의 운용사가 시장을 독과점할 위험이 있다. 특히, $\mathrm{OCIO}$ 시장은 진입장벽이 높아 OCIO 서비스를 공급할 수 있는 기업이 대형운용사로 한정될 가능성이 크다. 현실적으로 $\mathrm{OCIO}$ 운용비용 중에는 운용, 성과분석, 위험관리를 위한 시스템 구축 비용 등 사업자 선정 전에 발생하는 초기비용이 포함된다. 이와 같은 체계가 갖추어진 운용사가 OCIO 사업자 선정에 유리하며, 이러한 투자는 자본력과 인력이 풍부한 대형운용사에게 유리하다. 따라서 $\mathrm{OCIO}$ 시장 진입을 위한 초기비용의 비중이 높다는 점이 $\mathrm{OCIO}$ 시장의 공급자가 대형운용사로 좁혀지는 원인일 수 있다. 이처럼 $\mathrm{OCIO}$ 시장의 공급이 운용역량이 큰 운용사를 중심으로 독과점 형태를 띨 가능성이 크다는 점을 고려할 때, 민간 연기금 투자풀에 의존하면 $\mathrm{OCIO}$ 시장의 독과점 현상이 심화할 위험이 있다.

따라서 기금형 퇴직연금 도입 이후 OCIO 시장 규모가 충분히 성장하기 위해서는 OCIO가 자체적으로 기금을 총괄 운용하는 시스템을 구축하는 것이 중요하다. OCIO가 기금별로 전담조직을 구성하지 않고 총괄적으로 운용한다면 규모가 작은 기금도 $\mathrm{OCIO}$ 를 중심으로 하나의 투자풀을 형성하는 효과를 얻을 수 있어 비용부담이 줄어들게 된다. 현재 국내 OCIO 시장은 전담조직 구성을 요구하는 대형 공적 연기금을 중심으로 구성되어 있어 $\mathrm{OCIO}$ 사업자는 전담조직 구성에 맞춰 $\mathrm{OCIO}$ 체계를 갖춰나가고 있다. 그러나 총괄적 운영이 소규모 기금에 적합하다는 점에서 추후 $\mathrm{OCIO}$ 시장이 충분히 성장하기 위해서는 총괄적 운영을 고려한 $\mathrm{OCIO}$ 체계가 구성될 필요가 있다. 미래에셋자산과 한화운용, $\mathrm{KB}$ 자산운용은 새로운 펀드상품을 출시하는 방법으로 총괄적 운영 체계를 구축해가고 있다. 이들은 각각 '미래에셋 $\mathrm{OCIO}-\mathrm{DB}$ 표준형증권', '한화OCIO솔루션증권투자신탁(혼합-재간접형)', 'KB타겟리턴OCIO펀드'를 출시하였다.14) 이러한 상품은 연기금의 자산 배분 전략을 활용하여 중장기 목표수익률을 제시하는 구조로, 퇴직연금을 포함한 소규모 연기금을 주요 대상으로 한다. 이와 같은 구조에서는 하나의 민간 연기금 투자풀을 구성하는 경우보다는 규모가 작은 기금이 다수 생기기 때문에 효율성은 떨어질 수 있으나, 개별 운용사가 자신의 운용역량에 따라 활용할 수 있다.

\section{5. 결론}

본 논문은 대리인 문제를 중점적으로 다루던 기존 연구와 달리 OCIO 시장에서의 경쟁을 경제학 게임이론의 경매 모형을 통해 분석한다. $\mathrm{OCIO}$ 시장은 기금이 $\mathrm{OCIO}$ 를 선정하는 과정에서 조달 경매의 형태를 띤다. 이에 따라 본 논문에서는 개별 기금의 OCIO 선정 경쟁을 하나의 경매 게임으로 구성하여 기금과 $\mathrm{OCIO}$ 가 상호 연결되는 균형상황을 $\mathrm{OCIO}$ 가 기금을 운용하는 방식에 따라 두 가지로 나눠 분석한다. 첫 번째 운용방식은 기금별로 전담조직을 구성하여

14) 기금이 OCIO형 펀드상품을 통해 OCIO 서비스를 사용할 경우, 자신의 기준에 부합하는 OCIO 펀드상품을 선정한다는 점에서 본 연구의 조달 경매 방식과 유사한 의사결정 방식을 따른다. 그러나 하나의 기금이 여러 펀드상품에 가입할 수도 있다는 점에서는 조달 경매 방식과는 차이가 있을 수 있다. 
운용하는 형태이고, 두 번째는 OCIO가 여러 기금을 총괄적으로 운용하는 형태이다. 첫 번째 운용방식의 경우, 규모가 작은 기금은 전담조직을 구성하는데 드는 부담으로 인해 OCIO 서비스를 사용하기 어렵다. 반대로 두 번째 운용방식의 경우, OCIO가 여러 기금을 총괄적으로 운용하는 형태이기 때문에 규모가 작은 기금도 OCIO 서비스를 사용할 수 있다. 현재 OCIO 시장은 기금형 퇴직연금의 도입에 따라 시장 규모가 증가할 것으로 기대되어 공급자 측의 경쟁이 치열한 것으로 보인다. 그러나 현재와 같이 기금별로 전담조직을 구성하여 OCIO 서비스를 제공할 경우, 자산규모가 작은 기금은 $\mathrm{OCIO}$ 서비스를 사용하기 힘들 것으로 보인다. 이는 기금형 퇴직연금이 도입되더라도 소규모의 민간기금은 OCIO 서비스를 실질적으로 사용하기 힘들다는 것을 의미한다. 따라서 현재와 같은 구조가 유지될 경우, $\mathrm{OCIO}$ 시장이 지금의 기대만큼 성장할 것으로 보기 힘들다. $\mathrm{OCIO}$ 시장이 충분히 성장하기 위해서는 $\mathrm{OCIO}$ 가 기금을 총괄적으로 운용하는 시스템이 원활하게 구축될 필요가 있다.

본 연구는 OCIO 서비스 시장에서의 경쟁에 대한 경제학 게임이론 접근을 제시했다는 점에서 의의가 있다. 하지만 본 연구는 OCIO 시장의 균형을 직관적으로 파악하기 위해 단편적으로 모형을 구성했다는 점에서 한계가 있다. 이에 따라 추후 연구에서 두 가지 방향으로 본 연구 모형을 확장할 필요가 있다. 첫 번째는 다기간(multi-period) 모형으로의 확장이다. 다기간에 걸친 $\mathrm{OCIO}$ 선정 경쟁을 분석할 경우, 운용사가 $\mathrm{OCIO}$ 서비스를 제공한 경험 여부와 이전 계약에서의 성과 등이 서비스 품질을 변화시키는 요소로 작용할 수 있다. 두 번째는 성과보수를 반영한 확장이다. 본 연구에서는 운용보수만을 $\mathrm{OCIO}$ 서비스의 가격요소로 설정하였으나, 성과보수의 비중 확대에 대한 요구가 늘어나고 있는 만큼, OCIO 서비스의 가격요소에 성과보수를 포함할 필요가 있다. 이러한 확장은 대리인 문제를 모형에 반영할 수 있을 것이다. 또한, 운용보수만을 고려하는 현재의 모형에서는 OCIO로 선정되었을 때 운용사가 얻는 이익에 불확실성이 존재하지 않지만, 성과보수를 고려할 경우, OCIO 선정 이후의 운용사의 이윤이 불확실해진다는 차이가 생긴다. 즉, 성과보수를 고려할 경우, 운용사는 OCIO 선정으로 인한 이득을 정확히 파악할 수 없는 상황에서 경쟁하게 되므로, 과도한 입찰경쟁으로 승자의 저주에 빠질 수 있음을 의미한다. 이러한 방향으로 모형을 확장한다면 OCIO 시장에서의 경쟁과 균형에 대한 보다 현실적이고 포괄적인 설명을 할 수 있을 것이다. 
Competition in the Outsourced Chief Investment Officer Market

\section{References}

Anton, J. J., and D. A. Yao, 1992, Coordination in Split Award Auctions, Quarterly Journal of Economics, Vol. 107 (2), pp. 681-707.

Asker, J., and E. Cantillon, 2008, Properties of Scoring Auction, RAND Journal of Economics, Vol. 39 (1), pp. 69-81.

Asker, J., and E. Cantillon, 2010, Procurement When Price and Quality Matter, RAND Journal of Economics, Vol. 41 (1), pp. 1-34.

Bernheim, B. D. and M. D. Whinston, 1986, Menu Auctions Resource Allocation, and Economic Influence, Quarterly Journal of Economics, Vol. 101 (1), pp. 1-31.

Bergstresser, D., J. M. R. Chalmers, and P. Tufano, 2009, Assessing the Costs and Benefits of Brokers in the Mutual Fund Industry, Review of Financial Studies, Vol. 22 (10), pp. 4129-4156.

Blake, C. R., E. J. Elton, and M. J. Gruber, 1993, The Performance of Bond Mutual Funds, Journal of Business, Vol. 66 (3), pp. 371-403.

Che, Y. K., 1993, Design Competition through Multidimensional Auctions, RAND Journal of Economics, Vol. 24 (4), pp. 668-680.

Chen, J., H. Hong, W. Jiang, and J. D. Kubik, 2013, Outsourcing Mutual Fund management: Firm Boundaries, Incentives, and Performance, Journal of Finance, Vol. 68 (2), pp. $523-558$.

Chen, J., H. Huang, and R. J. Kauffman, 2011, A Public Procurement Combinatorial Auction Mechanism with Quality Assignment, Decision Support Systems, Vol. 51 (3), 480-492.

Chen, Z., 2021, The Multidimensional Procurement Auctions with Reference Based Utility, Managerial and Decision Economics, Vol. 42 (2), pp. 319-325.

Chief Investment Officer, 2020 Outsourced-Chief Investment Officer Survey, Retrieved from www.ai-cio.com.

Cho, S., 2014, Brokerage Commissions in Equity Funds in Korea, Journal of Money \& Finance, Vol. 28 (1), pp. 99-133.

Clark, G. L. and R. Urwin, 2017, The Outsourced Chief Investment Officer Model of Management and the Principal-agent Problem, Journal of Retirement, Vol. 4 (3), pp. 28-41.

Cuoco, D. and R. Kaniel, 2011, Equilibrium Prices in the Presence of Delegated Portfolio Management, Journal of Financial Economics, Vol. 101 (2), pp. 264-296.

Elton, E. J., M. J. Gruber, S. Das, and M. Hlavka, 1993, Efficiency with Costly Information: A Reinterpretation of Evidence from Managed Portfolios, Review of Financial Studies, Vol. 6 (1), pp. 1-22. 
한국증권학회지 제 50 권 5 호 (2021)

Guercio, D. D. and J. Reuter, 2014, Mutual Fund Performance and the Incentive to Generate Alpha, Journal of Finance, Vol. 69 (4), pp. 1673-1704.

Huang, J., C. Sialm, and H. Zhang, 2011, Risk Shifting and Mutual Fund Performance, Review of Financial Studies, Vol. 24 (8), pp. 2575-2616.

Ip, W. H., M. Huang, K. L. Yung, and D. Wang, 2003, Genetic Algorithm Solution for a Risk-based Partner Selection Problem in a Virtual Enterprise. Computers \& Operations Research, Vol. 30 (2), pp. 213-231.

Jenkinson, T., H. Jones, and J. V. Martinez, 2016, Picking Winners? Investment Consultants' Recommendations of Fund Managers, Journal of Finance, Vol. 71 (5), pp. 2333-2370.

Jensen, M. C., 1968, The Performance of Mutual Funds in the Period 1945 1964, Journal of Finance, Vol. 23 (2), pp. 389-416.

Kokott, G.-M., M. Bichler, and P. Paulsen, 2019, The Beauty of Dutch: Ex-post Split-award Auctions in Procurement Markets with Diseconomies of Scale, European Journal of Operational Research, Vol. 278 (1), pp. 202-210.

Kyle, A. S., H. Ou-Yang, and B. Wei, 2011, A Model of Portfolio Delegation and Strategic Trading, Review of Financial Studies, Vol. 24 (11), pp. 3778-3812.

Lee, J. H., C. Trzcinka, and S. Venkatesan, 2019, Do Portfolio Manager Contracts Contract Portfolio Management?, Journal of Finance, Vol. 74 (5), pp. 2543-2577.

Li, C. W. and A. Tiwari, 2009, Incentive Contracts in Delegated Portfolio Management, Review of Financial Studies, Vol. 22 (11), pp. 4681-4714.

Li, Z., J. Yue, and C.-C. Kuo, 2018, Design of Discrete Dutch Auctions with Consideration of Time, European Journal of Operational Research, Vol. 265 (3), pp. 1159-1171.

Liu, S., J. Li, and D. Liu, 2012, Multi-attribute Procurement Auctions with Risk Averse Suppliers, Economic Letters, Vol. 115 (3), pp. 408-411.

Ma, L., Y. Tang, and J.-P. Gomez, 2019, Portfolio Manager Compensation in the U.S. Mutual Fund Industry, Journal of Finance, Vol. 74 (2), pp. 587-638.

Mladineo, M., I. Veza, and N. Gjeldum, 2017, Solving Partner Selection Problem in Cyber-physical Production Networks Using the HUMANT Algorithm, International Journal of Production Research, Vol. 55 (9), pp. 2506-2521.

Ou-Yang, H., 2003, Optimal Contracts in a Continuous-time Delegated Portfolio Management Problem, Review of Financial Studies, Vol. 16 (1), pp. 173-208.

Papakonstantinou, A., and P. Bogetoft, 2017. Multi-dimensional Procurement Auction under Uncertain and Asymmetric Information, European Journal of Operational Research, Vol. 258 (3), pp. 1171-1180.

Paulsen, P., M. Bichler, and G.-M. Kokott, 2020, The Beauty of Dutch: Bidding Behavior 
Competition in the Outsourced Chief Investment Officer Market

in Combinatorial First-price Procurement Auctions, European Journal of Operational Research, Vol. 291 (2), pp. 711-721.

Ryu, D., and D. Park, 2020, Agency Problems Related to Outsourced Chief Investment Officers, Journal of Money \& Finance, Vol. 34 (3), pp. 33-60.

Shin, J. C., R. S. Park, and J. M. Chung, 2020, A Survey on Critical Success Factor of OCIO Business in Korea, Journal of Derivatives and Quantitative Studies, Vol. 28 (1), pp. 103-134.

Shin, J. H. and D. Lee, 2020, Evaluation Period and Agency Problem in Outsourced Chief Investment Officer (OCIO), Journal of Derivatives and Quantitative Studies, Vol. 28 (1), pp. 135-157.

Stoughton, N. M., Y. Wu, and J. Zechner, 2011, Intermediated Investment Management, Journal of Finance, Vol. 66 (3), pp. 947-980.

Stoughton, N. M., 1993, Moral Hazard and the Portfolio Management Problem, Journal of Finance, Vol. 48 (5), pp. 2009-2028.

Stracca, L., 2006, Delegated Portfolio Management: A Survey of the Theoretical Literature, Journal of Economic Surveys, Vol. 20 (5), pp. 823-848.

Won, C. H., 2006, The Optimal Portfolio for the Pension Fund Investors, Korean Journal of Financial Studies, Vol. 35 (4), pp. 191-221.

Yoon, S.-J. and S. Lee, 2019, Fee Structures of Outsourced CIO and the Operational Efficiency, Korean Journal of Futures and Options, Vol. 27 (3), pp. 275-296. 


\section{$\langle$ Appendix A〉}

식 (8)에 $\alpha_{n}=B\left(q_{n}\right)$ 을 대입하면 다음 식 (A.1)과 같다.

$$
\left(q_{n}-q_{0}\right)^{N-1}+(N-1)\left\{B\left(q_{n}\right)-f\left(F_{m}\right)\right\}\left(q_{n}-q_{0}\right)^{N-2} \cdot \frac{d q_{n}}{d B\left(q_{n}\right)}=0
$$

양변에 $\frac{d B\left(q_{n}\right)}{d q_{n}}$ 을 곱하면 식 (A.2)와 같다.

$$
\left(q_{n}-q_{0}\right)^{N-1} \cdot \frac{d B\left(q_{n}\right)}{d q_{n}}+(N-1)\left\{B\left(q_{n}\right)-f\left(F_{m}\right)\right\}\left(q_{n}-q_{0}\right)^{N-2}=0
$$

식 (A.2)를 식 (A.3)과 같이 정리할 수 있다.

$$
\left(q_{n}-q_{0}\right)^{N-1} \cdot \frac{d B\left(q_{n}\right)}{d q_{n}}+(N-1) \cdot B\left(q_{n}\right) \cdot\left(q_{n}-q_{0}\right)^{N-2}=(N-1) \cdot f\left(F_{m}\right) \cdot\left(q_{n}-q_{0}\right)^{N-2}
$$

식 (A.3)의 좌변은 $\left(q_{n}-q_{0}\right)^{N-1} \cdot B\left(q_{n}\right)$ 을 $q_{n}$ 으로 미분한 것과 같다. 따라서 식 (A.3)을 식 (A.4)와 같이 정리할 수 있다.

$$
\frac{d\left[\left(q_{n}-q_{0}\right)^{N-1} \cdot B\left(q_{n}\right)\right]}{d q_{n}}=(N-1) \cdot f\left(F_{m}\right) \cdot\left(q_{n}-q_{0}\right)^{N-2}
$$

식 (A.4)의 양변을 $q$ 에 대하여 적분해주면 식 (A.5)와 같다.

$$
\left(q_{n}-q_{0}\right)^{N-1} \cdot B\left(q_{n}\right)=\int_{q_{0}}^{q_{n}} f\left(F_{m}\right) \cdot\left\{(N-1) \cdot\left(q-q_{0}\right)^{N-2}\right\} d q
$$

식 (A.5)의 우변을 계산하면 다음 식 (A.6)과 같다.

$$
\int_{q_{0}}^{q_{n}} f\left(F_{m}\right) \cdot\left\{(N-1) \cdot\left(q-q_{0}\right)^{N-2}\right\} d q=f\left(F_{m}\right) \cdot\left(q-q_{0}\right)^{N-1}
$$

따라서 식 (A.5)와 식 (A.6)을 통해 다음 식 (A.7)이 도출된다.

$$
B\left(q_{n}\right)=f\left(F_{m}\right)
$$

정의에 따라 $\alpha_{n}=B\left(q_{n}\right)$ 이므로, 식 (8)에서 식 (9)이 도출됨을 확인할 수 있다.

\section{$\langle$ Appendix B〉}

식 (12)에 $\alpha_{n}=B\left(q_{n}\right)$ 을 대입하면 다음 식 (B.1)과 같다.

$$
\left(q_{n}-q_{0}\right)^{N-1}+(N-1)\left\{B\left(q_{n}\right)-g\left(q_{n}\right)\right\}\left(q_{n}-q_{0}\right)^{N-2} \cdot \frac{d q_{n}}{d B\left(q_{n}\right)}=0
$$

양변에 $\frac{d B\left(q_{n}\right)}{d q_{n}}$ 을 곱하면 식 (B.2)와 같다.

$$
\left(q_{n}-q_{0}\right)^{N-1} \cdot \frac{d B\left(q_{n}\right)}{d q_{n}}+(N-1)\left\{B\left(q_{n}\right)-g\left(q_{n}\right)\right\}\left(q_{n}-q_{0}\right)^{N-2}=0
$$

식 (B.2)를 식 (B.3)과 같이 정리할 수 있다. 
Competition in the Outsourced Chief Investment Officer Market

$$
\left(q_{n}-q_{0}\right)^{N-1} \cdot \frac{d B\left(q_{n}\right)}{d q_{n}}+(N-1) \cdot B\left(q_{n}\right) \cdot\left(q_{n}-q_{0}\right)^{N-2}=(N-1) \cdot g\left(q_{n}\right) \cdot\left(q_{n}-q_{0}\right)^{N-2}
$$

식 (B.3)의 좌변은 $\left(q_{n}-q_{0}\right)^{N-1} \cdot B\left(q_{n}\right)$ 을 $q_{n}$ 으로 미분한 것과 같다. 따라서 식 (B.3)을 식 (B.4)와 같이 정리할 수 있다.

$$
\frac{d\left[\left(q_{n}-q_{0}\right)^{N-1} \cdot B\left(q_{n}\right)\right]}{d q_{n}}=(N-1) \cdot g\left(q_{n}\right) \cdot\left(q_{n}-q_{0}\right)^{N-2}
$$

식 (B.4)의 양변을 $q$ 에 대하여 적분하면 식 (B.5)와 같다.

$$
\left(q_{n}-q_{0}\right)^{N-1} \cdot B\left(q_{n}\right)=\int_{q_{0}}^{q_{n}} g(q) \cdot\left\{(N-1) \cdot\left(q-q_{0}\right)^{N-2}\right\} d q
$$

식 (B.5)의 우변을 계산하면 다음 식 (B.6)과 같다.

$$
\int_{q_{0}}^{q_{n}} g(q) \cdot\left\{(N-1) \cdot\left(q-q_{0}\right)^{N-2}\right\} d q=g(q) \cdot\left(q_{n}-q_{0}\right)^{N-1}-\int_{q_{0}}^{q_{n}} g^{\prime}(q) \cdot\left(q-q_{0}\right)^{N-1} d q
$$

따라서 식 (B.5)와 식 (B.6)을 통해 다음 식 (B.7)이 도출된다.

$$
B\left(q_{n}\right)=g\left(q_{n}\right)-\frac{1}{\left(q_{n}-q_{0}\right)^{N-1}} \int_{q_{0}}^{q_{n}} g^{\prime}\left(q_{n}\right) \cdot\left(q-q_{0}\right)^{N-1} d q
$$

정의에 따라 $\alpha_{n}=B\left(q_{n}\right)$ 이므로, 식 (12)에서 식 (13)이 도출됨을 확인할 수 있다. 